\title{
Diagnóstico de ações coletivas rurais no Distrito Federal: um estudo no âmbito logístico
}

\author{
Diagnosis of rural collective actions in the Federal District: a study in logistic area
}

\author{
Vanessa Silva de Carvalho ${ }^{a}$ \\ Orcid: https://orcid.org/0000-0001-8503-205X
}

Amanda Cristina Gaban Filippi ${ }^{\text {b }}$

Orcid: https://orcid.org/0000-0001-5298-5348

Patrícia Guarnieri ${ }^{\mathrm{c}}$

Orcid: https://orcid.org/0000-0001-5298-5348

\begin{abstract}
Resumo
A disponibilidade para o armazenamento se torna cada vez mais importante no Agronegócio brasileiro, juntamente às mudanças organizações recentes enfrentadas pelos atores no setor de agronegócios. Tais mudanças se refletem na implementação de ações coletivas, como os Condomínios de Armazéns Rurais. Este trabalho, tem por objetivo analisar que tipos de ações coletivas rurais existem no Distrito Federal e entorno, e a relação existente com os Condomínios de Armazéns Rurais. Para atingir esse objetivo foi realizada uma revisão sistemática de literatura e um estudo de caso, os resultados de ambos os procedimentos foram analisados com base na técnica de Análise de Conteúdo proposta por Bardin (1966). Os principais resultados denotam que as ações coletivas rurais são caracterizadas em sua maioria por Associações ou Cooperativas no Distrito Federal e entorno de Goiás, e que aparentemente não existem Condomínios de Armazéns Rurais na região. Além disso, a região apresenta um considerável déficit de armazenagem e a maior parte das estruturas de armazenagem não são próprias, o que pode servir de motivação para a criação de novas estruturas de armazenagem como os Condomínios de Armazéns Rurais.
\end{abstract}

Palavras-chave: Ações coletivas. Agronegócio. Condomínios Rurais.

\begin{abstract}
The availability for warehousing becomes increasingly important in the Brazilian Agribusiness, along with current changes in organizations faced by the actors of agribusiness sector. These changes are reflected in collective actions, as such as the Condominiuns of Rural Warehouses. This paper aims to analyze what types of rural collective actions exist in the Distrito Federal, Brazil, besides analyse their relationship with the concept of Condominiuns of Rural Warehouses. For this purpose, it was carried outa systematic literature review and a case study. The results were and analysed through the technique of Content Analysis proposed by Bardin (1966). The main results show that rural collective actions are mostly characterized by Associations or Cooperatives in the Distrito Federal and vicinity. Besides there are apparently no one Condominium of Rural Warehouses in the region. In addition, the region has a shortage of storage and most of the warehouse structures are not proper. This result can be a motivator factor to the creation of new warehouse structures, as such asthe Condominiuns of Rural Warehouses.
\end{abstract}

Keywords: Collective actions. Agribusiness. Condominiuns of Rural Warehouses.

\footnotetext{
${ }^{a}$ Graduanda em Administração. UnB - Universidade de Brasília, Brasil. E-mail: vannyscarvalho@gmail.com

${ }^{\mathrm{b}}$ Doutoranda em Agronegócios - PPAGRO / UFG Professora Colaboradora FACE/UnB Mestre em Agronegócios - PROPAGA / UnB Engenheira Agrônoma - ESALQ / USP, Brasil. E-mail: amandagaban@hotmail.com

${ }^{\mathrm{c}}$ Doutora em Engenharia de Produção pela Universidade Federal de Pernambuco (UFPE). Professora adjunta do curso de Administração da Universidade de Brasília (UnB). Professora e orientadora no Programa de Pós-Graduação em Agronegócio e no Programa de PósGraduação em Administração da Universidade de Brasília (UnB), Brasil. E-mail: profpatriciaunb@gmail.com
} 


\section{INTRODUÇÃOO}

Devido à diversidade e às vantagens edafoclimáticas existentes, o Brasil apresenta as condições favoráveis para o cultivo de diferentes produtos agropecuários, como também uma considerável representatividade entre os principais países produtores e exportadores no setor do Agronegócio. Tais condições proporcionam à região Centro-Oeste uma liderança na produção e exportação de commodities como a soja (Companhia Nacional de Abastecimento - CONAB, 2018; Ministério da Indústria, Comércio Exterior e Serviços - MDIC, 2018).

No que se refere à produção de grãos, a safra de 2016/2017 obteve 222,91 milhões de toneladas. Esse número revela um crescimento de $19,5 \%$ em relação à safra $2015 / 16$, o que equivale a 36,3 milhões de toneladas a mais. Tal fato evidencia o crescimento e os consecutivos recordes a cada nova safra para a produção de grãos no país. Esses números ocasionam em determinados períodos do ano sobrecarga no sistema logístico de distribuição, como é o caso da atividade de armazenagem e plataformas exportadoras, evidenciando o déficit na armazenagem de grãos existente, o qual persiste em determinados períodos do ano, bem como, denota-se que existem estruturas obsoletas e antigas que não cumprem plenamente os objetivos a que se destinam (CONAB, 2018; FILIPPI, 2017; OLIVEIRA, 2011).

Uma armazenagem inadequada dos produtos pode ocasionar diminuição da qualidade, perda de competitividade, problemas de escoamento da produção, assim como problemas no transporte e estocagem (GABAN; GUARNIERI, 2015; OLIVEIRA, 2011). O déficit na armazenagem também é considerado um dos principais gargalos da logística. Por outro lado, quando a atividade de armazenagem é eficaz e eficiente gera benefícios principalmente em longo prazo (FILIPPI; GUARNIERI; FARIAS, 2017).
Considerando a crescente produção de grãos existente no país, o déficit de armazenagem e a sobrecarga e obsolescência nas estruturas de armazenagem, torna-se importante considerar a capacidade estática de armazéns. Adicionalmente, denota-se que as regiões Sul e Centro-Oeste representam $77 \%$ da capacidade total disponível no país (CONAB, 2018).

Diante desse cenário, começaram a ocorrer mudanças organizacionais recentes, as quais devem ser enfrentadas pelos atores envolvidos no setor de agronegócios. Tais mudanças são influenciadas por exigências nos níveis qualidade dos produtos, regularidade no fornecimento, preço de mercado e atividades logísticas (LOURENZANI; SILVA, 2006). Consequentemente, essas mudanças se refletem em novas formas de organizações rurais, que resultam em ações coletivas (WENNINGKAMP; SCHMIDT, 2016), como é o caso dos Condomínios de Armazéns Rurais. Os Condomínios de Armazéns Rurais são um tipo de associação que tem por finalidade a cooperação de agricultores vizinhos para a criação de um armazém compartilhado como alternativa a outros modelos de cooperação rural. Essa alternativa de associação ou ação coletiva gera alguns benefícios, como por exemplo, a redução de custos com o processo de armazenagem, distribuição, comercialização estratégica do produto, melhor preço pago ao produtor rural, entre outros (FILIPPI, 2017; FILIPPI et al., 2018).

Dessa forma, o objetivo desse artigo é analisar que tipos de ações coletivas rurais existem no Distrito Federal e entorno, bem como, se existe relação delas com o conceito de Condomínios de Armazéns Rurais. Para tanto, foi realizada uma revisão sistemática da literatura com base no protocolo de Cronin, Ryan e Coughlan (2008) e um estudo de caso com base na Empresa de Assistência Técnica e Extensão Rural do Governo do Distrito Federal (EMATER-DF). Os dados foram coletados 
por meio da entrevista semiestruturada e análise documental e foram analisados por meio da técnica de análise de conteúdo (BARDIN, 1977).

Os principais resultados denotam que as ações coletivas são caracterizadas em sua maioria por Associações ou Cooperativas no Distrito Federal e entorno de Goiás. Além disso, aparentemente, não existem Condomínios de Armazéns Rurais na região de Brasília e entorno, essa situação pode ser explicada em parte pelas características da propriedade de terras do DF, as quais, em grande parte são pertencentes à Federação, o que significa que o Distrito Federal confere ao produtor rural direito ao uso da terra, mas não the transfere a proprietária, de forma que a terra não é regularizada. Dessa forma, os produtores rurais, pequenos e médios, não podem conceder a propriedade como garantia caso recorram a financiamentos bancários para adquirir estruturas de armazenagem.

\section{LOGÍSTICA NO AGRONEGÓCIO BRASILEIRO: IMPORTÂNCIA DA ARMAZENAGEM E GARGALOS NO CENTRO-OESTE}

A logística como elemento macro, integra todas as atividades e parceiros existentes em uma cadeia produtiva, como a gestão de suprimentos, apoio à produção, distribuição, além da logística reversa. No Agronegócio Brasileiro, como em qualquer outro setor a gestão logística se torna fundamental, pois envolve o planejamento de suprimentos, o controle de estoques, controle da informação, bem como atividades relativas à distribuição do produto acabado, como armazenagem e transporte e, se necessário, abrange também o fluxo reverso de retorno dos produtos, embalagens e equipamentos (ARAÚJO, 2013; BALLOU, 2006).

Nesse sentido, Araújo (2013) descreve que a logística é presente no Agronegócio em três momentos. No primeiro momento se aciona a logística de suprimentos, a qual é dedicada ao tratamento e movimentação dos insumos agropecuários, do fornecedor até a propriedade rural; em um segundo momento, se aciona a logística de apoio à produção agropecuária, a qual é iniciada após a colheita da produção através das atividades de manuseio da produção, estocagem, armazenagem , além dos controles de fluxos e informações; em um terceiro momento, se evidencia a logística de distribuição que se reflete nas atividades de transporte dos produtos até o distribuidor ou consumidor final. Vale lembrar que, no Agronegócio grande parte dos produtos são perecíveis, assim deve se considerar que a perecibilidade é um fator importante, o que demanda que o manuseio, embalagem, estocagem, armazenagem e transporte necessitem de cuidado e adaptação para reduzir o desperdício de alimentos na (ARAÚJO, 2013; BALLOU, 2006; CAIXETA FILHO, 2010).

Assim, a atividade de armazenagem pode ser considerada muito importante para evitar tais desperdícios, principalmente devido às condições sazonais da produção e comercialização (ARAÚJO, 2013; FILIPPI, 2017). Para Bowersox e Closs (2001), a armazenagem apresenta elementos vantajosos para toda cadeia produtiva. Entre esses elementos, destacam-se vantagens econômicas e a consolidação de cargas, que minimizam as quantidades de produtos nos depósitos e a centralização das cargas em um único local, reduzindo custos logísticos. Adicionalmente, a armazenagem pode ser realizada individualmente, pela própria empresa, com recursos próprios ou ainda, terceirizada ou compartilhada entre um grupo de indivíduos. (BOWERSOX; CLOSS, 2001).

Outro objetivo da armazenagem é garantir a integridade e qualidade ao produto ao abrigá-lo em local adequado e seguro, bem como, protegido de intempéries climáticas. Além disso, pode ser considerada estratégica para o negócio, tendo em vista proporcionar que a venda do produto seja realizada em um melhor 
momento, considerando a oferta e a demanda do mercado (MESQUITA; MACEDO; BARBOSA, 2007).

Entretanto, a armazenagem apresenta alguns gargalos (GABAN; GUARNIERI, 2015). No caso dos armazéns de propriedades rurais, esses possuem baixa capacidade estática e não suportam o excedente da produção a cada nova safra. Nesse sentido, o excesso de produção, juntamente com seu escoamento, desencadeia alguns problemas logísticos como congestionamento de redes de abastecimentos, terminais lotados, e comercialização da safra por preços muito baixos (Instituto de Estudos Avançados IEA, 2011; FILIPPI, 2017).

Nesse cenário, a estimativa da safra 2017/18 revela uma produção de 229,7 milhões de toneladas, mais um recorde na safra brasileira de grãos, principalmente para soja e milho. Quanto à armazenagem, a capacidade estática para a região do Centro-Oeste revela disponibilidade de 58.692,5 mil toneladas em 2017, sendo que a produção na região foi $100.240,7 \mathrm{mil}$ toneladas (CONAB, 2018) (Figura 1). Tais números evidenciam a representatividade da Região Centro-Oeste e a necessidade de estruturas adequadas de armazenagem na região.

Figura 1 - Evolução da produção de grãos e capacidade de armazenagem.

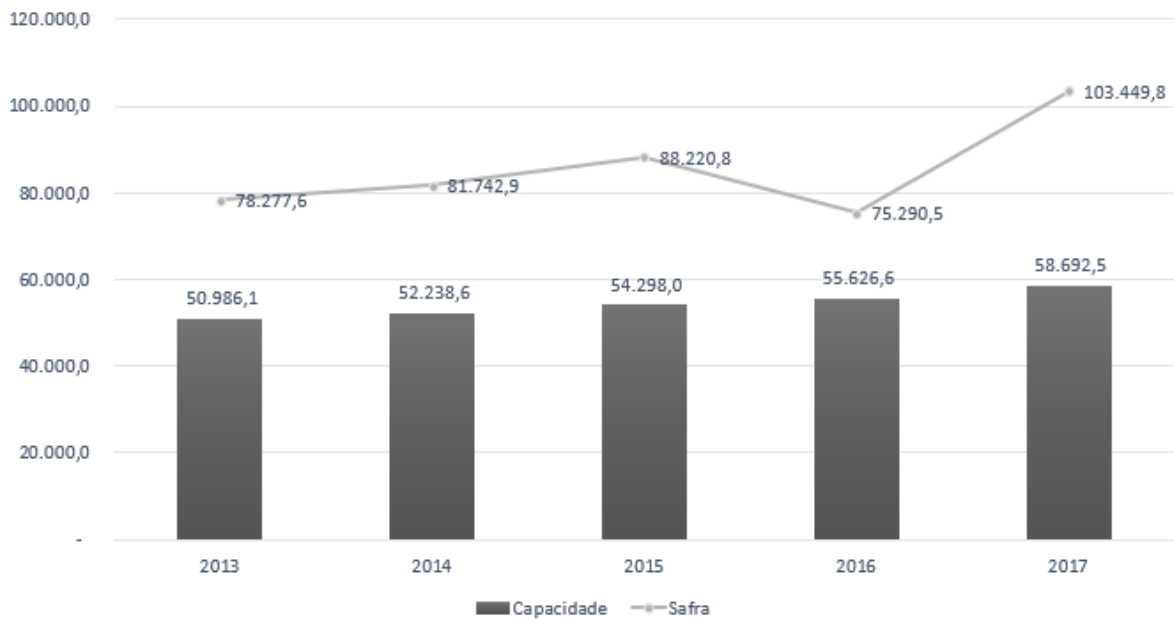

Fonte: Adaptado de CONAB (2018).

A Figura 1 ilustra a evolução da produção na Região Centro-Oeste e a capacidade estática de armazenagem na região entre 2013 e 2017. Observa-se que a safra no referido período teve um aumento e também, que a capacidade estática dos armazéns aumentou. Contudo, denota-se que a capacidade estática ainda é insuficiente $\mathrm{e}$, portanto, evidencia-se a necessidade no aumento dessa capacidade para suprir a demanda de produção estimada. A próxima seção trata sobre as Ações Coletivas no Agronegócio.

\section{AÇÕES COLETIVAS NO AGRONEGÓCIO}

O agronegócio possui um papel estratégico no desenvolvimento do país, principalmente pela participação no PIB e considerando a geração de empregos e renda. Dessa forma, as relações econômica, social e comercial, que ocorrem entre os agentes envolvidos em toda cadeia agroalimentar, são fundamentais para $o$ crescimento e desenvolvimento do país. O associativismo rural é uma das formas de organização desses atores a fim de obter vantagens em termos de comercialização em escala, redução de custos e melhor 
acesso a fontes de financiamento. Uma vez que os atores rurais se unem em associações, tornam-se mais fortes na competição do mercado (GARRIDO; SEHNEM, 2006). Ademais, novos padrões no ambiente rural são traçados, principalmente relacionados aos pequenos produtores rurais, que contribuem para $o$ aumento da qualidade, regularidade no fornecimento, melhores preços $\mathrm{e}$ otimização logística (LOURENZANI; SILVA, 2006).

Wenningkamp e Schmidt (2016) relatam que as ações coletivas são uma forma de organização caracterizada pela atuação conjunta de indivíduos e/ou firmas, que unem esforços para atingir objetivos comuns, de maneira eficiente.

Para Hardin (2004), as ações coletivas são interações sociais movidas por um mesmo objetivo, de forma a demandar ações conjuntas para atingi-lo. As ações coletivas são estabelecidas, principalmente se o objetivo da união for ligado a aspectos econômicos de interesse dos indivíduos participantes, além disso, o tamanho do grupo não depende somente da quantidade de interessados em participar e sim do montante de quantidade, mas sim de ações realizadas (OLSON, 1967).

Ademais, as ações coletivas têm por base uma ação coordenada coletiva ou uma ação realizada por dois ou mais indivíduos, podendo apresentar variações em cada situação. Porém, mesmo essa base sendo igual para todos, os tipos de ações coletivas apresentam (OLSON, 1967), as quais podem ser encontradas no setor de Agronegócio como redes de produtores, cooperativas, associações, clusters, arranjos produtivos locais (APL) e aglomerados de produtores SCHMIDT, 2016).

(WENNINGKAMP;

O Quadro 1 exemplifica algumas semelhanças e diferenças entre os modelos e ações coletivas.

Quadro 1-Descrição de ações coletivas rurais.

\begin{tabular}{|l|l|}
\hline $\begin{array}{l}\text { TIPO DE AÇÃO } \\
\text { COLETIVA }\end{array}$ & CARACTERÍSTICAS \\
\hline Redes & $\begin{array}{l}\text { Integração, ganho mútuo, ação coletiva institucionalizada (ZYLBERSZTAJN; } \\
\text { FARINA, 2006). }\end{array}$ \\
\hline Cooperativas & $\begin{array}{l}\text { Armazenagem coletiva, compras e vendas coletivas, finalidade comercial, modelo de } \\
\text { negócio (RIOS, 2007; OCB, 2018; ZYLBERSZTAJN, 1985). }\end{array}$ \\
\hline Associações & Cooperação, finalidade assistencial (MAPA, 2016). \\
\hline Cluster & $\begin{array}{l}\text { Múltipla utilização de estrutura física, cooperação e competição empresarial } \\
\text { (ARAÚU, 2013; ZACCARELLI et al., 2008). }\end{array}$ \\
\hline APL e Aglomerado & Proximidade territorial, aglomeração de empresas (ARAÚJO, 2013). \\
\hline $\begin{array}{l}\text { Condomínios de de } \\
\text { Armazéns Rurais }\end{array}$ & $\begin{array}{l}\text { Proximidade territorial (vizinhos), estrutura própria de armazenagem, divisão em cotas, } \\
\text { partes da armazenagem, e obtenção de vantagens e benefícios do sistema (FILIPPI, } \\
\text { 2017; FILIPPI } \text { et al., 2018). }\end{array}$ \\
\hline
\end{tabular}

Fonte: Adaptado de Araújo (2013); Filippi (2017); Filippi et al. (2018); OCB (2018); Ottonelli (2000); Rios

(2007); Sebrae (2018); Zylbersztajn (1985); Zylbersztajn e Farina (2006); Wenningkamp e Schmidt (2016); Zaccarelli et al. (2008).

Quando se aborda a definição de redes no âmbito da ação coletiva, Zylbersztajn e Farina (2006) relatam que apresentam ganho mútuo, de forma igualitária em um sistema de cooperação, caracterizada como uma ação coletiva institucionalizada. Para Zaccarelli et al. (2008) as redes assim como os clusters, possuem vantagem por localização geográfica, mas o elemento chave das redes é a integração.

Quanto ao Cooperativismo, é um modelo de ação coletiva que acaba sendo generalizado para vários tipos, entretanto deve-se atentar para evitar erros conceituais (RIOS, 2007; OCB, 2018). O Cooperativismo é uma organização na qual cada membro produz produtos iguais ou diferentes e cujos produtos combinados 
satisfazem

uma

necessidade

(ZYLBERSZTAJN, 1985). Além disso, o Cooperativismo é um modelo de negócio, com objetivos comuns, no qual os cooperados se beneficiam por meio de compras e vendas coletivas, e de armazéns coletivos (OCB, 2018).

O Associativismo rural é uma ação coletiva na qual os produtores rurais, geralmente pequenos e médios, viabilizam projetos coletivos. Tal associação auxilia economicamente esses produtores a competir no mercado e obter vantagens no sistema comercial (como por exemplo comercialização estratégica considerando a oferta e demanda), obtenção de benefícios econômicos, principalmente em redução de custos e, em termos sociais devido à inclusão socioprodutiva e consequente geração de renda (Ministério da Agricultura, Pecuária e Abastecimento MAPA, 2018).

Outro grupo de ações coletivas apontado por Wenningkamp e Schmidt (2016) são os Clusters, os quais são arranjos produtivos locais e aglomerados. Os clusters podem ser caracterizados como ações coletivas de atividades semelhantes e de proximidade geográfica, com necessidade de atividades correlatas e a presença simultânea de cooperação e de competição (WENNINGKAMP; SCHMIDT, 2016). Para Araújo (2013), cluster é um aglomerado de empresas que se encontram interligadas entre si em uma mesma região, com vantagem sinérgica, aproveitamento mais eficiente dos produtos e utilização conjunta da estrutura física. Zaccarelli et al. (2008) concordam com Araújo (2013), acrescentando que cluster é um modelo menos conhecido e semelhante às redes, já que, geograficamente agrupa empresas, atividades relacionadas, competição e cooperação.

Já os Arranjos Produtivos Locais (APL) caracterizam-se como "aprofundamento da visão de clusters" (ARAÚJO, 2013, p. 21). Para o mesmo autor, APL envolve a organização de cadeias produtivas em determinada localidade e também a inter-relação dessas cadeias produtivas com outros setores, o que é corroborado pelo MDIC(2018).

Por fim, os Condomínios de Armazéns Rurais, se caracterizam por apresentar proximidade territorial entre produtores rurais, estrutura própria de armazenagem, divisão em cotas partes da armazenagem, e obtenção de vantagens e benefícios do sistema (FILIPPI, 2017; FILIPPI et al., 2018; FILIPPI; GUARNIERI, 2019).Os Condomínios Rurais são um novo modelo de ação coletiva na forma de colaboração entre produtores próximos que buscam uma maneira de se beneficiarem por meio da armazenagem, ou outra atividade agropecuária, ou investimento próprio em armazéns graneleiros (FILIPPI et al., 2018; FILIPPI, 2017).

Não há fontes sobre a origem do modelo e como surgiu, contudo, existem registros sobre o desenvolvimento deles por volta da década de 80 e 90 na região Sul do país devido à necessidade de buscar soluções para alterar o sistema produtivo tradicional de leite em pequenas propriedades rurais (OLIVO, 2000). Mais recentemente, houve a expansão do modelo entre diferentes atividades agropecuárias (FILIPPI, 2017), como: leiteira (OLIVO; POSSAMAI, 2000; GULLO, 2001;), suína (ANJOS; MOYANO ESTRADA; CALDAS, 2011; MOYANO-ESTRADA; ANJOS, 2001), agroenergética (DE PAULA et al., 2011; ALMEIDA et al., 2017) e logística (FILIPPI et al., 2018; FILIPPI, 2017).

Com o desenvolvimento desse modelo, os Condomínios de Armazéns Rurais passaram a se estruturar com o intuito de reduzir o déficit de armazenagem, desencadeando benefícios para os produtores rurais (FILIPPI, 2017; FILIPPI et al., 2018). Para Olivo (2000), os Condomínios Rurais têm iniciativa privada que intensificam práticas entre produtores próximos. $\mathrm{O}$ autor também destaca a caracterização dada pela Empresa Brasileira de Assistência Técnica do estado do Rio 
Grande do Sul (EMATER/RS) sobre os Condomínios leiteiros, os quais são considerados como instrumentos de viabilização da propriedade pela união dos produtores, que em parceria, conseguem produzir, vender ou comprar insumos ou produtos agropecuários (OLIVO, 2000). Tal modelo também se caracteriza como solidário e no caso específico dos armazéns, existe a divisão em cotas (FILIPPI, 2017).

De acordo com o $\S 1^{\circ}$ do artigo 2 do Decreto $\mathrm{n}^{\mathrm{o}} 3.993$ de 30 de outubro de 2011 da Presidência da República, o Condomínio Rural é definido como:

Agrupamento de pessoas físicas ou jurídicas constituído em sociedade por cotas, mediante fundo patrimonial pré-existente, com o objetivo de produzir bens, comprar e vender, prestar serviços, que envolvam atividades agropecuárias, extrativistas vegetal, silviculturais, artesanais, pesqueiras e agroindústrias, cuja duração é por tempo indeterminado.

Ademais, esse modelo voltou a emergir nos últimos anos e está se estruturando em algumas regiões do Brasil, sendo que a região Sul é a que atualmente tem mais iniciativas já consolidadas e também são considerados os pioneiros no estabelecimento desse tipo de estrutura entre os produtos rurais (FILIPPI, 2017).

Por fim, as principais semelhanças entre os modelos de ações coletivas estão na proximidade geográfica, como nas redes, clusters, APL, aglomerados e Condomínios Rurais. Quanto às suas principais diferenças, destaca-se a formalização da estrutura organizacional e a criação dos tipos de ações coletivas, podendo ser de caráter empresarial ou não, como também o alcance do mercado e a competição.

Nota-se proximidade entre as definições de ações coletivas dos diferentes autores. Assim, entende-se como ações coletivas aquelas empreendidas coletivamente por diferentes indivíduos, os quais buscam objetivos comuns e se unem para alcançá-los de maneira eficiente e rentável.

\section{MÉTODOS E TÉCNICAS DE PESQUISA}

A pesquisa tem por intuito analisar questões da realidade, unindo a teoria com os métodos científicos (MINAYO, 1994; DEMO, 1996). De acordo com o objetivo desse estudo, essa pesquisa é classificada como aplicada, exploratória, descritiva e qualitativa (SILVA; MENEZES, 2001). Os procedimentos técnicos utilizados foram a revisão da literatura e o estudo de caso. A revisão sistemática é um tipo de levantamento da literatura, que tem a função de fornecer uma explicação objetiva, afunilada e robusta do que já existe publicado sobre determinado assunto (CRONIN; RYAN; COUGHLAN, 2008).

Tal procedimento visa ainda reunir informações sobre determinado tema a partir de fontes diversas e estabelecimento de critérios, bem como a análise do conteúdo das publicações (CRONIN; RYAN; COUGHLAN, 2008). Gil (2002) relata a importância da utilização de leitura crítica a fim de identificar informações e dados, estabelecer relações, e analisar a consistência delas, a qual foi utilizada nesta pesquisa.

Dessa forma, a revisão sistemática de literatura contempla as seguintes etapas:

(i) Definição do objetivo da pesquisa: analisar quais ações coletivas rurais existem no Distrito Federal e entorno, bem como, a existência de relação dessas com os Condomínios de Armazéns Rurais.

(ii) Determinação dos critérios de inclusão e exclusão: as plataformas selecionadas para a pesquisa foram o Portal de Periódicos da CAPES, Google Acadêmico e Scielo. O período de busca definido foi entre janeiro/1998 a junho/2018. As palavras-chave utilizadas foram "ações coletivas", "agronegócio", "armazenamento" e "condomínios de armazéns'. Também foi determinada a 
escolha das publicações em meios de comunicação. Os documentos poderiam ser dissertações, teses, artigos e relatórios oriundos do governo, com a exclusão de capítulos de livros, patentes e artigos sem informações quanto à procedência. Para esta pesquisa foi utilizado apenas $o$ operador booleano $A N D$ para fazer a interseção entre as palavras-chave.

(iii) Seleção e acesso de literatura incluída na revisão: no Portal de Periódicos da CAPES foram levantados 206 artigos e selecionados apenas os que apresentaram aderência com as palavraschave definidas, o que resultou em 5 artigos. A aderência considera somente artigos que se situam no escopo do tema de pesquisa, os mecanismos de busca frequentemente apresentam resultados que são dissociados das palavras-chave escolhidas e que não possuem relação com o tema da pesquisa, porque muitas vezes dissociam palavras compostas. No Google Acadêmico também foram selecionados apenas 5 artigos, de um total de 69.400 publicações, e na Scielo apenas 2 documentos. Totalizaram-se, então, 10 documentos que tinham relação com o problema de pesquisa. Documentos repetidos foram eliminados.

(iv) Avaliação dos documentos selecionados: as publicações foram examinadas em detalhes de acordo com a leitura analítica proposta por Gil (2002). Foi identificada a definição de ações coletivas utilizada em cada publicação, bem como identificada que tipo de ação coletiva específica se referia. (v) Análise, síntese e disseminação dos resultados: os documentos obtidos foram analisados, sintetizados em quadros e discutidos.

Por fim, a unidade do estudo de caso foi definida como a Empresa de Assistência Técnica e Extensão Rural do Distrito Federal EMATER. O instrumento de coleta de dados foi um roteiro de entrevista semiestruturado, o qual foi aplicado em três unidades diferentes da EMATER do Distrito Federal: a sede, no Ceasa e no PADF. Os entrevistados foram denominados de $\mathrm{A}, \mathrm{B}$ e $\mathrm{C}$ para resguardar a confidencialidade dos dados. Adicionalmente, ressalta-se que a escolha ocorreu seguindo os critérios de acessibilidade e representatividade, tendo em vista que os entrevistados detinham a informação requerida pela pesquisa.

Como método adicional para a coleta de dados foi conduzida uma análise documental e depois, na qual foram considerados documentos disponíveis em sites governamentais a fim de levantar informações sobre os Condomínios de Armazéns Rurais no Distrito Federal e Goiás. A fim de analisar os resultados encontrados com base nas entrevistas e análise documental, foi realizada a análise de conteúdo, essa possibilitou categorizar o conteúdo das entrevistas, definindo-se as categorias aprioristicamente (BARDIN, 1977). Os resultados foram também confrontados com a literatura a fim de analisar se a prática corresponde com a teoria.

\section{ANÁLISE E DISCUSSÃO DOS RESULTADOS}

\subsection{Resultados da Revisão Sistemática de Literatura}

O Quadro 1 apresenta os documentos selecionados da revisão sistemática de literatura. 
Quadro 1 - Resultados da Revisão Sistemática de Literatura.

\begin{tabular}{|c|c|c|c|c|}
\hline Título & Autores & $\begin{array}{c}\text { Instituição/ } \\
\text { Periódico }\end{array}$ & Objetivo & Principais Resultados \\
\hline $\begin{array}{l}\text { Sustentabilidade de } \\
\text { condomínios rurais } \\
\text { formados por } \\
\text { pequenos } \\
\text { agricultores } \\
\text { familiares: análise e } \\
\text { proposta de modelo } \\
\text { de gestão. }\end{array}$ & $\begin{array}{l}\text { Olivo } \\
(2000)\end{array}$ & $\begin{array}{l}\text { Tese } \\
\text { UFSC }\end{array}$ & $\begin{array}{l}\text { Analisar, com base no } \\
\text { Desenvolvimento } \\
\text { Sustentável, e contexto da } \\
\text { cooperação agrícola, a } \\
\text { propriedade condominial } \\
\text { RS e propor um modelo } \\
\text { de gestão para a formação } \\
\text { de novas associações. }\end{array}$ & $\begin{array}{l}\text { Elaboração de um modelo de } \\
\text { gestão sustentável, com } \\
\text { ênfase na propriedade } \\
\text { condominial de agricultores } \\
\text { familiares. }\end{array}$ \\
\hline $\begin{array}{lr}\text { As } & \text { estratégias } \\
\text { competitivas } & \mathrm{e} \\
\text { colaborativas } & \text { os } \\
\text { resultados } & \\
\text { individuais } & \mathrm{e} \\
\text { coletivos } & \text { no } \\
\text { associativismo rural } \\
\text { em Quatro Pontes } \\
\text { (PR). }\end{array}$ & $\begin{array}{l}\text { Kunzler e } \\
\text { Bulgavoc } \\
(2010)\end{array}$ & $\begin{array}{l}\text { UNIOESTE } \\
\text { FGV } \\
\text { RAP }\end{array}$ & $\begin{array}{l}\text { Compreensão de que } \\
\text { forma as estratégias de } \\
\text { competição e de } \\
\text { colaboração existentes } \\
\text { nas associações de } \\
\text { produtores rurais } \\
\text { influenciam os resultados } \\
\text { individuais e coletivos } \\
\text { obtidos pelos produtores } \\
\text { participantes. }\end{array}$ & $\begin{array}{l}\text { Esse estudo demonstra a } \\
\text { influência que estratégias de } \\
\text { competição e colaboração } \\
\text { que existem nas associações } \\
\text { de produtores rurais } \\
\text { influenciam nos resultados } \\
\text { individuais e coletivos de } \\
\text { produtores participantes. }\end{array}$ \\
\hline $\begin{array}{lr}\text { Condições } & \text { de } \\
\text { viabilidade } & \text { da } \\
\text { implantação de uma } \\
\text { unidade } & \text { de } \\
\text { armazenamento } & \text { de } \\
\text { grãos em uma } \\
\text { propriedade rural no } \\
\text { município } & \text { de } \\
\text { Redentora-RS. } & \\
\end{array}$ & $\begin{array}{l}\text { Ottonelli } \\
\text { (2011) }\end{array}$ & UNIJUÍ & $\begin{array}{l}\text { Estudo de viabilidade } \\
\text { técnica e econômica da } \\
\text { implementação de uma } \\
\text { unidade de } \\
\text { armazenamento de grãos } \\
\text { em uma propriedade } \\
\text { rural. }\end{array}$ & $\begin{array}{l}\text { O estudo demonstra que a } \\
\text { armazenagem da produção } \\
\text { na propriedade é altamente } \\
\text { lucrativa. Entre as vantagens } \\
\text { está em conseguir melhores } \\
\text { preços, venda de subprodutos } \\
\text { e melhores fretes em } \\
\text { entressafras. }\end{array}$ \\
\hline $\begin{array}{l}\text { Ações Coletivas no } \\
\text { Agronegócio: } \\
\text { uma análise da } \\
\text { produção científica } \\
\text { no Brasil a partir de } \\
\text { teses e dissertações } \\
(1998-2012) .\end{array}$ & $\begin{array}{l}\text { Wenningk } \\
\text { amp e } \\
\text { Schmidt } \\
(2016 a)\end{array}$ & $\begin{array}{l}\text { UNIOESTE } \\
\text { RESR }\end{array}$ & $\begin{array}{l}\text { Compreensão } \text { da } \\
\text { produção científica no } \\
\text { Brasil sobre ações } \\
\text { coletivas no agronegócio, } \\
\text { a partir de testes e } \\
\text { dissertações defendidas } \\
\text { no período de } 1998 \text { a } \\
2012 \text {. }\end{array}$ & $\begin{array}{l}\text { Os resultados mostram } \\
\text { pesquisas envolvidas com } \\
\text { ações coletivas no } \\
\text { Agronegócio e seu aumento } \\
\text { nos últimos anos. O } \\
\text { segmento agropecuário foi o } \\
\text { mais pesquisado (estudos de } \\
\text { caso) e existe maior } \\
\text { concentração de formas } \\
\text { coletivas nas regiões Sul } \\
\text { Sudeste. }\end{array}$ \\
\hline $\begin{array}{l}\text { Teorias da Ação } \\
\text { Coletiva no Campo } \\
\text { do Agronegócio. }\end{array}$ & $\begin{array}{l}\text { Wenningk } \\
\text { amp e } \\
\text { Schmidt } \\
\text { (2016b) }\end{array}$ & $\begin{array}{l}\text { UNIOESTE } \\
\text { Desenvolvi } \\
\text { mento em } \\
\text { Questão }\end{array}$ & $\begin{array}{l}\text { Análise dos resultados } \\
\text { teórico-empíricos de } \\
\text { teses e dissertações sobre } \\
\text { ações coletivas no } \\
\text { agronegócio, defendidas } \\
\text { entre } 1998 \text { e 2012, à luz } \\
\text { de teorias da ação } \\
\text { coletiva. }\end{array}$ & $\begin{array}{l}\text { Os resultados demonstram a } \\
\text { existência de benefícios } \\
\text { econômicos, sociais, } \\
\text { ambientais e culturais devido } \\
\text { à ação coletiva. }\end{array}$ \\
\hline $\begin{array}{l}\text { As ações coletivas } \\
\text { sob a forma de } \\
\text { cooperativas e a } \\
\text { relevância na cadeia } \\
\text { produtiva da soja no } \\
\text { Paraná. }\end{array}$ & $\begin{array}{l}\text { Campos e } \\
\text { Lago } \\
(2016)\end{array}$ & $\begin{array}{l}\text { UFMG e } \\
\text { UNIOESTE } \\
\text { Economia e } \\
\text { Região }\end{array}$ & $\begin{array}{l}\text { Discussão da influência } \\
\text { das ações coletivas, com } \\
\text { foco nas cooperativas em } \\
\text { relação á cadeia } \\
\text { produtiva da soja do PR. }\end{array}$ & $\begin{array}{l}\text { As ações coletivas, sob a } \\
\text { forma de cooperativas, têm } \\
\text { tido forte influência sobre a } \\
\text { cadeia produtiva da soja do } \\
\text { PR, na produção, } \\
\text { processamento e distribuição } \\
\text { da soja paranaense. }\end{array}$ \\
\hline
\end{tabular}




\begin{tabular}{|c|c|c|c|c|}
\hline Título & Autores & $\begin{array}{c}\text { Instituição/ } \\
\text { Periódico }\end{array}$ & Objetivo & Principais Resultados \\
\hline $\begin{array}{l}\text { Políticas para } \\
\text { arranjos produtivos } \\
\text { locais no Brasil. }\end{array}$ & $\begin{array}{l}\text { Lastres et } \\
\text { al. }(2016)\end{array}$ & BNDES & $\begin{array}{l}\text { Mapeamento e análise } \\
\text { das políticas para arranjos } \\
\text { produtivos locais no } \\
\text { Brasil. }\end{array}$ & $\begin{array}{l}\text { Os principais resultados } \\
\text { mostram que as ações } \\
\text { produtivas avançaram, } \\
\text { contudo ainda são pontuais } \\
\text { em determinados locais. } \\
\text { Além disso, não existe } \\
\text { articulação estratégica para } \\
\text { as necessidades locais e } \\
\text { desenvolvimento sistêmico. }\end{array}$ \\
\hline $\begin{array}{lr}\text { Caracterização } & \text { e } \\
\text { análise } & \text { da } \\
\text { viabilidade } & \text { de } \\
\text { condomínios de } & \text { de } \\
\text { armazéns rurais: um } \\
\text { estudo Multicaso. }\end{array}$ & $\begin{array}{l}\text { Filippi } \\
\text { (2017) }\end{array}$ & $\begin{array}{c}\text { Dissertação } \\
\text { UnB }\end{array}$ & $\begin{array}{l}\text { Análise das } \\
\text { características, } \\
\text { perspectivas e viabilidade } \\
\text { para a estruturação de } \\
\text { Condomínios de } \\
\text { Armazéns Rurais de grão } \\
\text { no Brasil. }\end{array}$ & $\begin{array}{l}\text { Os Condomínios de } \\
\text { Armazéns Rurais são uma } \\
\text { organização empreendedora, } \\
\text { que apresenta diversas } \\
\text { vantagens provenientes do } \\
\text { sistema de armazenagem e } \\
\text { do sistema condominial, que } \\
\text { reduzem custos e aumentam } \\
\text { o lucro. }\end{array}$ \\
\hline $\begin{array}{l}\text { Evolução da } \\
\text { produção de grãos e } \\
\text { armazenagem: } \\
\text { perspectivas } \\
\text { agronegócio do } \\
\text { brasileiro para } \\
\text { 2024/25. }\end{array}$ & $\begin{array}{l}\text { Gaban et } \\
\text { al. (2017) }\end{array}$ & $\begin{array}{l}\text { UnB } \\
\text { Informe } \\
\text { Gepec }\end{array}$ & $\begin{array}{l}\text { Análise da evolução e } \\
\text { importância } \\
\text { Agronegócio do } \\
\text { produção de grãos e do } \\
\text { setor de armazenamento, } \\
\text { com vistas às } \\
\text { perspectivas atuais e } \\
\text { futuras. }\end{array}$ & $\begin{array}{l}\text { O setor de armazenamento } \\
\text { não acompanha o ritmo de } \\
\text { crescimento da produção de } \\
\text { grãos, há uma distribuição } \\
\text { desigual entre os locais que } \\
\text { mais produzem grãos e entre } \\
\text { os locais que mais } \\
\text { apresentam espaço físico } \\
\text { para armazenar os produtos } \\
\text { agrícolas. Os benefícios que } \\
\text { a armazenagem proporciona } \\
\text { deixam de ser usufruídos e } \\
\text { menos de } 15 \% \text { dos armazéns } \\
\text { se concentram nos locais de } \\
\text { produção. }\end{array}$ \\
\hline $\begin{array}{l}\text { Ações coletivas no } \\
\text { agronegócio: Uma } \\
\text { análise do estado da } \\
\text { arte a partir dos } \\
\text { Congressos r da } \\
\text { SOBER } \\
\text { 2013). }\end{array}$ & $\begin{array}{l}\text { Schmidt et } \\
\text { al. (2018) }\end{array}$ & $\begin{array}{l}\text { UNIOESTE } \\
\text { RAMA }\end{array}$ & $\begin{array}{l}\text { Compreensão do estado } \\
\text { da arte em ações coletivas } \\
\text { no agronegócio, por meio } \\
\text { da análise dos } \\
\text { Congressos da Sober, no } \\
\text { período de } 2004 \text { a } 2013 \text {. }\end{array}$ & $\begin{array}{l}\text { Os principais resultados } \\
\text { apontam a solidificação das } \\
\text { ações coletivas no } \\
\text { Agronegócio e aumento no } \\
\text { número de trabalhos sobre } \\
\text { elas. }\end{array}$ \\
\hline
\end{tabular}

Fonte: Resultados da Pesquisa (2018).

Os resultados evidenciam que o maior número de publicações sobre o tema se concentra no ano de 2016 (WENNINGKAMP; SCHMIDT, 2016a; WENNINGKAMP; SCHMIDT, 2016b; CAMPOS; LAGO, 2016; LASTRES et al.,2016). Isso evidencia que é um tema recente considerando a maior quantidade de publicações sobre as ações coletivas no Agronegócio.

Em relação às instituições das quais são provenientes os pesquisadores, a
Universidade Estadual do Oeste do Paraná (UNIOESTE) revelou estar presente em metade dos documentos dessa revisão sistemática de literatura. Tal fato se deve à UNIOESTE contemplar um Programa de Pós-Graduação em Desenvolvimento Regional e Agronegócio, focos do objetivo de pesquisa dessa revisão sistemática de literatura, como também estudos e pesquisas com ênfase na temática. Já em relação à natureza dos documentos, existe diversificação entre periódicos, dissertação 
e tese, com maiores publicações sendo em periódicos.

Ademais, foi identificado que o estudo sobre as ações coletivas das publicações selecionadas nessa revisão sistemática de literatura está ligado às temáticas: (i) logística e armazenagem (FILIPPI, 2017; GABAN et al., 2017; OTTONELLI, 2011); (ii) Condomínios Rurais (OLIVO, 2000; FILIPPI, 2017); (iii) estratégias de competição e colaboração (KUNZLER; BULGAVOC, 2010); (iv) revisão de literatura (WENNINGKAMP; SCHMIDT, 2016a; WENNINGKAMP; SCHMIDT, 2016b; SCHMIDT et al., 2018); (v) cooperativismo (CAMPOS; LAGO, 2016); e,(vi) arranjos produtivos (LASTRES et al., 2016).

Além disso, essas publicações evidenciam algumas características específicas que existem na logística agroindustrial e nas ações coletivas do país, como o déficit no setor de armazenagem brasileiro e vantagens que as ações coletivas podem proporcionar ao negócio agrícola, como também sua consolidação e fortalecimento nos últimos nos no Agronegócio.

\subsection{ANÁLISE DE CONTEÚDO: AÇÕES COLETIVAS}

Esta seção apresenta os resultados da análise de conteúdo (BARDIN, 1977). Foram elaboradas quatro categorias temáticas: (i) Categoria 1: Organização e caracterização das ações coletivas; ii) Categoria 2: Caracterização da produção agrícola nas ações coletivas rurais; (iii) Categoria 3: Percepção e caracterização da Armazenagem; e, (iv) Categoria 4: Percepção sobre ações coletivas.

O Quadro 2 resume os principais resultados obtidos a partir de entrevista com as três unidades da EMATER, os resultados foram organizados nas categorias definidas aprioristicamente.

Quadro 2 - Síntese dos resultados da pesquisa

\section{i. Representatividade de ações coletivas como Associações e Cooperativas no}

$\mathrm{DF}$;

Categoria 1: Organização e

ii. Incentivo a práticas coletivas rurais no DF, como Associações;

Caracterização das ações coletivas

iii. A comunidade é participativa quanto ao encaminhamento de demandas para os técnicos de extensão rural a fim de conseguir melhorias nas atividades rurais.

i. Existe uma maior concentração da produção de FLV em Brasília (unidades

Categoria 2: Caracterização da produção agrícola nas ações coletivas rurais administrativas) e existe uma maior concentração da produção de grãos, soja e milho, no entorno do Distrito Federal;

ii. Grande parte da terra cultivada pelos produtores rurais do DF pertence ao Estado;

iii. Déficit de armazenagem no DF

i. A armazenagem é realizada principalmente por Cooperativas no DF;

ii. Os produtores não conseguem realizar a comercialização estratégica da

Categoria 3: Percepção e caracterização Armazenagem

da produção devido à insuficiência de armazéns;

iv. Maior quantidade de armazéns no DF não são próprios $(65,1 \%)$;

iv. Potencial para criação e desenvolvimento de Condomínios de Armazéns Rurais e novas unidades armazenadoras.

i. O modelo atual de ação coletiva do DF prevalece sendo de Associações e Cooperativas;

ii. Não conhecimento quanto ao modelo de Condomínios Rurais.

Fonte: Resultados da pesquisa (2018).

A primeira categoria buscou compreender o perfil de organização das ações coletivas no DF. Os entrevistados A, B e C relataram que o serviço de extensão técnica rural do governo atende principalmente pequenos e médios produtores rurais do Distrito Federal e entorno, independentemente do tipo de ação coletiva que eles participam ou 
da forma como estão organizados, sendo que as ações coletivas que mais prevalecem na região são Associações e Cooperativas.

Além disso, as atuações do serviço de extensão técnica e assistência rural do governo são locais. Não existem trocas de informações entre unidades pela unidade da federação, mesmo com a existência de unidades em diversos estados e cidades. Assim, como cada unidade da EMATER gerencia uma região específica, as informações concentram-se naquela gerência.

Nesse intuito, os técnicos desenvolveram um instrumento de trabalho para levantar algumas informações das comunidades locais, o Índice de Desenvolvimento Comunitário (IDCR). Esse instrumento apresenta um relatório final contemplando informações sobre cada Unidade Local da EMATER/DF e dados sobre as comunidades de abrangência do local, com dimensões humana, social, tecnológica, econômica, ecológicaambiental, político-institucional e demográfica-territorial (EMATER, 2018). Nesses relatórios não existem informações sobre o tipo de ação coletiva da região de estudo. Contudo, os entrevistados relataram que as ações coletivas que prevalecem na região são Associações e Cooperativas, sem qualquer conhecimento de Condomínios Rurais, e que o número total das organizações na região é aproximadamente duas mil.

Ademais, os entrevistados relataram que as comunidades locais não se comunicam com outras comunidades de outros estados. Contudo, muitos produtores rurais se relacionam com próximos, dado que pertencem a mesmas Associações, como em atividades de comercialização e intercâmbio de conhecimento. Entretanto, as atividades individuais das unidades produtivas não são interligadas, devido à diferença entre tipos de produções.

$\mathrm{O}$ entrevistado $\mathrm{C}$, ainda relatou que, devido à convivência nas comunidades rurais, algumas decisões coletivas precisam ser tomadas, e podem existir divergências entre os produtores. Dessa forma, a EMATER auxilia intervindo para evitar conflitos, como foi o caso da crise hídrica no Distrito Federal que ocorreu nos últimos meses.

Quanto ao incentivo a práticas coletivas rurais, os entrevistados $\mathrm{A}$ e $\mathrm{C}$ da EMATER relataram que existe um incentivo para a criação de Associações entre os produtores e, posteriormente, Cooperativas. Contudo, esses também relataram que é difícil manter "viva" uma Cooperativa, devido à redução de associados e burocracia para sua criação. Já no caso dos Condomínios Rurais existem facilidades para sua criação e os processos burocráticos são mais simples, o que seria um incentivo para essa formação (FILIPPI, 2017).

Por fim, os produtores rurais da região participam ativamente de reuniões e eventos, bem como, diversas propostas e demandas das comunidades locais são encaminhadas ao serviço de extensão técnica e rural do governo, tanto EMATER, como apoio da EMBRAPA ou SEAGRI.

A segunda e terceira categorias procuraram compreender como é a produção agrícola nas ações coletivas rurais e a armazenagem da região. Os entrevistados $\mathrm{A}, \mathrm{B}$ e $\mathrm{C}$ relataram que a produção agrícola em Brasília é representada em sua maioria por frutas, legumes e verduras (FLV), e a produção agrícola do entorno de Brasília (próximo ao PADF) é caracterizada por grãos, principalmente soja e milho. Além disso, toda produção segue normas de padronização.

Tal fato evidencia a necessidade de condições adequadas de armazenagem. Em Brasília, 35\% dos produtores rurais fazem uso de estruturas próprias de armazenagem, incluindo o uso de silos bags (estrutura de armazenagem temporária e que não pode ser reutilizada) e $65,1 \%$ não têm a própria estrutura de armazenagem. Isso gera desvantagens ao produtor rural (EXPEDIÇÃO SAFRA-BRASÍLIA, 2016). Caso $o$ produto seja armazenado, o 
armazém será coletivo, como em uma Cooperativa, por exemplo, e haverá descontos de taxas sobre aquele produto, como também, o produtor enfrenta filas em picos de safras e não poderá vender a produção estrategicamente em momento de melhor preço no mercado.

No caso da armazenagem própria, seja na forma de silo na própria unidade produtiva ou Condomínio de Armazém Rural, tal vantagem é usufruída, permitindo sua comercialização estratégica (FILIPPI, 2017; FILIPPI et al., 2018). Dessa forma, faltam armazéns graneleiros para a armazenagem adequada de grãos no DF, o que representa vantagem para criação e desenvolvimento de Condomínios de Armazéns Rurais e novas unidades armazenadoras.

Ademais, Brasília apresenta uma característica particular quanto à posse da terra. A maior parte das terras agrícolas pertence ainda ao Distrito Federal. Isso gera problemas aos produtores rurais caso necessitem recorrer a financiamentos, como por exemplo, para armazéns, já que, eles não possuem a propriedade da terra e não podem usá-la como garantia. A ausência do título da terra, além de desestimular os produtores a realizarem investimentos na propriedade, desestimula a sucessão familiar (EXPEDIÇÃO SAFRABRASÍLIA, 2016).

Por fim, a última categoria aborda a percepção do serviço de extensão técnica rural em relação às ações coletivas da região. Os entrevistados $\mathrm{A}, \mathrm{B}$ e $\mathrm{C}$ responderam que $\mathrm{o}$ modelo atual de organizações na região prevalece como Associações e Cooperativas, sendo que Associações apresentam a vantagem para os pequenos produtores de terem acesso aos programas governamentais, taxas mais baixas do que Cooperativas, e a entrada e saída é menos burocrática. Contudo, os produtores rurais não são donos, os patrimônios são da Associação, como também parte dos ganhos.

De acordo com Wenningkamp e Schmidt (2016), quanto maior o número de atores envolvidos num grupo, maior será a complexidade e dificuldade do negócio, principalmente caso a gestão e administração sejam ineficazes e ineficientes, e sem transparência. No caso dos Condomínios de Armazéns Rurais, toda estrutura é própria dos produtores rurais, os ganhos são $100 \%$ dos produtores e o número de associados é menor, em torno de 15 a 25 condôminos (FILIPPI, 2017; FILIPPI et al., 2018).

Adicionalmente, foi citado um caso único na região que um dos entrevistados tinha conhecimento sobre uma forma incomum de relacionamento entre membros de mesma família: "há dois produtores de uma mesma família que compartilham o armazenamento na propriedade". Tal caso exemplificado se aproxima do modelo de Condomínios de Armazéns Rurais, o qual, os condôminos podem ser familiares e objetivam dividir a mesma estrutura de armazenagem (FILIPPI, 2017).

Por fim, comparativamente aos resultados encontrados com a revisão sistemática de literatura, dentre as ações coletivas rurais que foram identificadas na revisão, e as identificadas no estudo de caso, apenas a forma de Associações e Cooperativas se evidenciaram em Brasília e entorno. Esses achados não anulam outras formas de ações coletivas que possam existir na região. Para tal propósito, seria necessário um levantamento de campo sistemático, com posterior cadastro detalhado dos tipos de ações coletivas que possam existir.

\section{CONSIDERAÇÕES FINAIS}

O objetivo deste trabalho foi analisar que tipos de ações coletivas rurais existem no Distrito Federal e entorno, bem como, se existe relação delas com os Condomínios de Armazéns Rurais. Através da revisão sistemática de literatura e da análise de conteúdo, por meio da categorização temática foi possível analisar os dados obtidos. 
Da revisão sistemática de literatura, os principais resultados identificados foram: a atualidade do tema sobre ações coletivas rurais no Agronegócio brasileiro, principalmente nos últimos três anos, sendo o maior número de publicações encontrado nos anos de 2016 a 2018. Além disso, destaca-se que os estudos sobre ações coletivas foram relacionados à logística e armazenagem, Condomínios Rurais, estratégias de competição e colaboração, cooperativismo e arranjos produtivos. Por fim, as publicações evidenciam gargalos na logística agroindustrial, como o déficit de armazenagem e vantagens que as ações coletivas podem proporcionar ao Agronegócio Brasileiro, como a consolidação do negócio agrícola e fortalecimento das atividades rurais.

Quanto à análise de conteúdo, foi possível elaborar e analisar quatro categorias de resultados. A primeira categoria analisou o perfil das organizações e caracterizava as ações coletivas. A segunda categoria buscou compreender a produção agrícola nas ações coletivas rurais. A terceira categoria objetivou compreender a percepção e caracterização da armazenagem. E a quarta categoria buscou ter a percepção do serviço de extensão técnica e de assistência em relação às ações coletivas da região de estudo.

Da primeira categoria os principais resultados indicam que predominam no Distrito Federal e entorno ações coletivas do tipo Associações e Cooperativas. Há também incentivo a práticas coletivas no DF e a comunidade rural é participativa quanto à solução de problemas e busca pelo crescimento e desenvolvimento do negócio agrícola.

A segunda categoria evidencia uma maior concentração na produção de FLV na região central de Brasília e maior concentração de grãos, soja e milho, no entorno do DF. Além disso, grande parte das terras são pertencentes ao Distrito Federal, o que gera algumas dificuldades aos produtores rurais locais, como acesso a financiamentos.
A terceira categoria mostra que existe déficit de armazenagem em Brasília e entorno, e que a maioria das unidades armazenadoras identificadas no estudo não são próprias, o que gera gargalos logísticos em épocas de picos de safra e a não comercialização estratégica da produção. A análise dessas características permite inferir que existem fatores motivadores para a criação e o desenvolvimento de Condomínios de Armazéns Rurais, ou novas unidades armazenadoras nessa localidade. Por fim, a última categoria evidencia novamente o prevalecimento de ações coletivas de Associações e Cooperativas na região, e a inexistência de Condomínios de Armazéns Rurais em Brasília e entorno.

Essa pesquisa limita-se a estudar a existência das ações coletivas no Distrito Federal e entorno e se há relação das ações existentes com o conceito de condomínios de armazéns rurais, portanto não analisa se existe a viabilidade financeira ou operacional para a instalação de condomínios. Também se limita à análise da percepção da EMATER e não envolve outras organizações relacionados à armazenagem como Conab e CNA, cuja percepção já foi publicada em estudos anteriores. A revisão sistemática se limita aos critérios estabelecidos no protocolo estabelecido, estudos com critérios diferentes podem gerar resultados diversos.

Para estudos futuros, sugere-se a análise da percepção dos produtores rurais de Brasília e entorno, cuja pesquisa não foi possível devido a não acessibilidade de um cadastro nacional sobre as ações coletivas que existem no país, e, estudos com outras unidades da EMATER em outros estados. Ademais sugere-se que os resultados sejam confrontados com estudos focados em outras unidades da federação, bem como estudos que analisem a viabilidade financeira e operacional da instalação de condomínios, com base em métodos já consolidados na literatura. 


\section{Agradecimentos}

Os autores agradecem a Fundação de Apoio

à Pesquisa do Distrito Federal (FAP/DF) pelo fomento ao projeto de pesquisa de qual este artigo faz parte e, à EMATER/DF pela disponibilidade e troca de conhecimentos.

\section{Referências}

ALMEIDA, C. et al. Analysis of the socio-economic feasibility of the implementation of an agroenergy condominium in western Paraná - Brazil. Renewable and Sustainable Energy Reviews, 75, p. 601-608, 2017.

ARAÚJO, M. J. Fundamentos de agronegócios, 4. ed. São Paulo: Atlas, 2013.

BALLOU, R. Gerenciamento da Cadeia de Suprimentos/Logística Empresarial. 5. ed. São Paulo: Atlas, 2006.

BARDIN, L. Análise de Conteúdo. 6. ed. São Paulo: Persona, 1977.

BOWERSOX, D.J.; CLOSS, D.J. Logística Empresarial. 1. ed. São Paulo: Atlas, 2001.

CAIXETA FILHO, J. Logística para a agricultura brasileira. Revista Brasileira de Comércio Exterior, 103, p.18-30, 2010.

CAMPOS, L. F.; LAGO, S.M.S.er. As ações coletivas sob a forma de cooperativas e a relevância na cadeia produtiva da soja no Paraná. Economia \& Região, v. 4, n. 2, p. 6184, jul/dez. 2016.

COMPANHIA NACIONAL DE ABASTECIMENTO - CONAB. Série Histórica de Produção X Capacidade Estática. Disponível em: http://www.conab.gov.br. Acesso em: 17 mar. 2018.

CRONIN, P.; RYAN, F.; COUGHLAN, M. Undertaking a literature review: a step-by-step approach. British Journal of Nursing, v. 17, n. 1, p. 38-43, 2008.

DEMO, P. Metodologia Científica em Ciências Sociais. São Paulo: Atlas, 1995.

EMPRESA DE ASSITÊNCIA TÉCNICA E EXTENSÃO RURAL DO DISTRITO FEDERAL - EMATER. Índice de Desenvolvimento Comunitário Rural - IDCR. Disponível em: http://www.emater.df.gov.br/indice-desenvolvimento-comunitario-rural. Acesso em: 18 jun. 2018 .

EXPEDIÇÃO Safra Brasília. Soja, milho safrinha e culturas irrigadas: diagnóstico e prospecção de demandas para pesquisa, extensão rural e política pública: relatório da Expedição Safra Brasília 2016, Distrito Federal. Sebastião Márcio Lopes de Andrade; Francisco Eduardo de Castro Rocha; Breno Rodrigues Lobato, editores técnicos. - Brasília, DF: Seagri-DF: Emater-DF: Ceasa-DF: Embrapa-Cerrados, 2017.

FILIPPI, A.C.G. Caracterização e análise da viabilidade de Condomínios de Armazéns Rurais: um estudo Multicaso. 2017, 204 f. Dissertação. (Mestrado em Agronegócio) Faculdade de Agronomia e Medicina Veterinária, Universidade de Brasília, Brasília, 2017. 
FILIPPI, A; GUARNIERI, P; FARIAS, J. Logística Agroindustrial: Uma Revisão Sistemática nos Anais de Congresso da Sober. Revista em Agronegócio e Meio Ambiente, Paraná, v. 10, n. 4, p. $1077-1112$, out/dez 2017.

FILIPPI, A.C.G.; GUARNIERI, P.; CARVALHO, J. M.; SOUZA, C.; CRUZ, J.E. Análise das forças, fraquezas, oportunidades e ameaças para os Condomínios de Armazéns Rurais. IGepec, Toledo, v. 22, n.1, p. 43-62, jan./jun. 2018.

FILIPPI, A.C.G.; GUARNIERI, P. Novas formas de organização rural: os Condomínios de Armazéns Rurais. Rev. Econ. Sociol. Rural, Brasília, v. 57, n. 2, p. 270-287, jun. 2019.

GABAN, A.C; GUARNIEIRI, P. Identificação de Gargalos na Logística Agroindustrial: Revisão Sistemática da Literatura. 2015. João Pessoa... In: CONGRESSO DA SOCIEDADE BRASILEIRA DE ECONOMIA, ADMINISTRAÇÃO E SOCIEDADE RURAL, 53., 2015. Anais [...]. 2015. 19 p.

GABAN, A.C.; MORELLI, F.; BRISOLA, M.V.; GUARNIERI, P. Evolução da produção de grãos e armazenagem: perspectivas do agronegócio brasileiro para 2024/25. IGepec, Toledo, v. 21, n. 1, p. 28-47, jan./jun. 2017.

GARRIDO, L.; SEHNEM, S. Gestão Associativa no Empreendimento Rural. Revista de Administração, v. 5, n. 8, jun.2006.

GIL, A. Como Elaborar Projetos de Pesquisa. 4. ed. São Paulo: Atlas, 2002.

GULLO, M.C.R. Fundo estadual de apoio ao desenvolvimento dos pequenos estabelecimentos rurais-FEAPER: uma análise dos 10 anos, com ênfase no problema da inadimplência. 2001. 147p. Dissertação (mestrado) - Universidade Federal do Rio Grande do Sul, Porto Alegre, 2001.

INSTITUO DE ECONOMIA AGRÍCOLA - IEA. Pontos críticos da armazenagem de grãos no Brasil. Disponível em: http://www.iea.sp.gov.br. Acesso em: 02 jun. 2018.

KUNZLER, M; BULGACOV, S. As estratégias competitivas e colaborativas e os resultados individuais e coletivos no associativismo rural em Quatro Pontes (PR). Revista de Administração Pública, Rio de Janeira, v. 45, n. 5, p. 363 - 369, set/out 2011.

LASTRES, Helena. M.M; GARCEZ, C; KAPLAN, E; et. al. Políticas para arranjos produtivos locais no Brasil. In: CAMPOS, L et al (Org). Políticas estaduais para arranjos produtivos locais no Sul, Sudeste e Centro-Oeste do Brasil. Rio de Janeiro: E-Papers, 2010.p. 35-40.

LOURENZANI, A.E.B.S.; SILVA, A.L. Ações Coletivas envolvendo pequenos produtores: da exclusão à inclusão nos mercados. Fortaleza. In: CONGRESSO DA SOCIEDADE BRASILEIRA DE ECONOMIA E SOCIOLOGIA RURAL, 44., 2006, Anais [...]. 2006. 19 p.

MESQUITA, J.L; MACEDO, M.S; BARBOSA, A.C. Avaliação do Sistema Brasileiro de Armazenagem Convencional e a Granel: Um estudo apoiado em análise envoltória de dados. 2007. Londrina. In: CONGRESSO DA SOCIEDADE BRASILEIRA DE ECONOMIA, ADMINISTRAÇÃO E SOCIEDADE RURAL, 45., 2007. Anais [...]. 2007. 21 p. 
MINAYO, M. C. de S. Pesquisa social: teoria método e criatividade. 17. ed. Petrópolis, RJ: Vozes, 1994.

MINISTÉRIO DA AGRICULTURA, PECUÁRIA E ABASTECIMENTO - MAPA. Cooperativismo. Disponível em: http://www.agricultura.gov.br/assuntos/cooperativismoassociativismo. Acesso em: 18 maio 2018.

MOYANO-ESTRADA, E.; dos ANJOS, F. S. New forms of economic cooperation in family agriculture: the case of condominios in Santa Catarina, Brazil. Journal of Rural Cooperation, v. 29, n. 1, 2001.

PAULA, G. et al. Suinocultores da agricultura familiar do município de Marechal Cândido Rondon (PR). Revista ADMpg Gestão Estratégica, Ponta Grossa, v. 4, n. 1, p.19-26, 2011.

SCHMIDT, C; TOMIO, M; WENNINGKAMP, K; TOMÉ, L; CIELO, I. Ações Coletivas no Agronegócio: uma análise do estado da arte a partir congressos da Sober (2004-2013). Revista em Agronegócio e Meio Ambiente, Paraná, v. 11, n. 1, p. 31 - 52, jan/mar 2018.

SEBRAE - SERVIÇO BRASILEIRO DE APOIO ÀS MICRO E PEQUENAS EMPRESAS. Entenda as diferenças entre associações e cooperativas. Disponível em: http://www.sebrae.com.br. Acesso em: 26 abr. 2018.

SILVA, E.; MENEZES, E. Metodologia de Pesquisa e Elaboração de Dissertação. 3. ed. Florianópolis - Laboratório de Ensino a Distância da UFSC, 2001.

Organização das Cooperativas do Brasil - OCB. O que é Cooperativismo. Disponível em http://www.ocb.org.br/o-que-e-cooperativismo. Acesso em: 21 jul. 2018.

OLIVEIRA, A.L.R. A logística agroindustrial frente aos mercados diferenciados: principais implicações para a cadeia da soja. Informações Econômicas, SP, v. 41, n. 6, jun. 2011.

OLIVO, C.J. Sustentabilidade de condomínios rurais formados por pequenos agricultores familiares: análise e proposta de modelo de gestão. 2000. 269p. Tese (doutorado) Universidade Federal de Santa Catarina, Florianópolis, 2000.

OLIVO, C.J.; POSSAMAI, O. Análise da sustentabilidade de Condomínios Rurais formados por agricultores familiares. Revista Extensão Rural, DEAER/CPGExR - CCR - UFSM, ano VIII, jan/dez 2000.

OLSON, M. The Logic of Collective Action. 3. ed. Cambridge: Indiana University, 1967.

OTTONELli, D. Condições De Viabilidade Da Implantação De Uma Unidade De Armazenamento De Grãos Em Uma Propriedade Rural No Município De Redentora-Rs. 2011, 40 p. Universidade Regional Do Noroeste Do Estado Do Rio Grande Do Sul, Ijuí, 2011.

TEIXEIRA, E. B. A análise de dados na pesquisa científica: importância e desafios em estudos organizacionais. Desenvolvimento em questão, v. 1, n. 2, p. 177-201, 2003. 
WENNINGKAMP, K; SCHMIDT, C. Ações Coletivas no Agronegócio: uma análise da produção científica no Brasil a partir de teses e dissertações (1998-2012). Revista de Economia e Sociologia Rural, São Paulo, v. 54, n. 3, p. 413 - 436, jul/set 2016.

WENNINGKAMP, K; SCHMIDT, C. Teorias da Ação Coletiva no Campo do Agronegócio Uma Análise a Partir de Teses e Dissertações (1998-2012). Desenvolvimento em Questão. Editora: Unijui, Rio Grande do Sul, ano 14, n. 35, p. 307 - 343, jul/set 2016.

ZACCARELLI, S.B.; TELLES, R.; SIQUEIRA, J.P.L.; BOAVENTURA, J.M.G.; DONAIRE, D. Clusters e Redes de Negócios: uma nova visão para a gestão dos negócios. São Paulo: Atlas, 2008.

ZYLBERSZTAJN, D. Papel dos Contratos na Coordenação Agro-Industrial: um olhar além dos mercados. Revista de Economia e Sociologia Rural, Rio de Janeiro, v. 43, n. 3, p. 385 - 420, $\mathrm{jul} / \mathrm{set} 2005$.

ZYLBERSZTAJN, D; FARINA, E. Dynamics of Network Governance: A Contribution to the Study of Complex Forms. School of Economic sand Business, Universidade de São Paulo. São Paulo, 2006. 